\title{
DIELECTRIC PROPERTIES OF LIQUID FOODS AFFECTED BY MOISTURE CONTENTS AND TEMPERATURES
}

*Ghanem, T.H.

\section{ABSTRACT}

The use of microwave energy is of growing interest due to brief time, volumetric heating due to its penetration and reduced processing time, making it an attractive source of thermal energy. The main objective of the present work is to study the effect of milk and tomato, strawberries juices temperatures and moisture contents, dry basis, on dielectric constant, loss tangent, loss factor and penetration depth at $2450 \mathrm{MHz}$ affecting heat and mass transfer by microwave. It was found that the dielectric constant increased by increasing moisture contents, temperatures and increasing the ability of material to store energy. Dielectric constant and dielectric loss factor are exponentially satisfied with coefficients of determinations between0.84-0.91 for tomato and strawberries. The dielectric constant of milk satisfied a linear form with coefficients of determinations between 0.88-0.97. The loss tangent is deceased with increasing the moisture content indicating the energy lost or dissipated by the material, and satisfied a power form with coefficients of determinations ranged between0.75-0.98 for all tested materials.

\section{INTRODUCTION}

The ASAE (1994) reported that the dependence of dielectric
properties of gains and seeds on temperature is not well
documented, and the only information included shelled corn. Theraja (1993) reported that every medium is supposed to posses absolute and relative pemittivity. He added that for measuring relative pemittivity, vacuum or free space is chosen as the reference medium. It is allotted an absolute pemittivity of $8.854 \times 10^{-12} \mathrm{farad} / \mathrm{m}$. Karmas (1980) mentioned that the variation of dielectric constant of moisture containing materials is approximately linear over a limited range from low to above $30 \%$ moisture content at room temperature. He stated that the dielectric

*Assoc. Prof., Agric. Eng.. Fac. of Agric., Al-Azhar Univ. 
constant of water is 81 , whereas, those of most organic bone-dry materials range from 2.2 to 4.0 .

Mujumdar (2000) reported that radiation with frequencies that range from $300 \mathrm{MHz}$ to $300 \mathrm{GHz}$ are normally referred to as microwaves, and the heat effect that occurs in this frequency range is known as microwave heating. He added that there are interferences between microwave, radio frequencies and radar frequency. He also reported that the properties governing the success of a material being heated by microwave field are the dielectric constant and loss factor which are related to electrical permittivity and loss tangent. Toledo (1991) reported that microwave, like light, is a from of electromagnetic vibration. Heat transfer is dependent on the degree of excitability of the molecules in the absorbing material and frequency of the field to which the medium is exposed. Dielectric heating is the term employed when relatively low frequencies are used and that the material is placed between to electrodes to which an electric current is passed. Frequencies from 60 to $100 \mathrm{MHz}$ may be used for dielectric heating. Microwave heating refers to the use of electromagnetic waves of very high frequency, making it possible to transmit the energy through space. The most common frequencies used for microwave heating are 2450 and $915 \mathrm{MHz}$. Domestic micwave ovens operate at $2450 \mathrm{MHz}$. The equations which govern heat transfer by microwave and dielectric systems are the same.

Mullin (1995) explained that the microwaves are reflected by metals, transmitted by electrically neutral materials such as glass, most plastics, ceramics and paper, and absorbed by electrically charged materials. Microwave penetrates deeply into food materials and as they penetrate, the energy they carry is converted to heat.

\section{MATERIALS AND METHODS}

In the present study dielectric properties: dielctric constant, loss factor, loss tangent or dissipation factor and penetration depth were studied in the Agricultural Engineering Department, Faculty of Agriculture, Al-Azhar University, Nasr City. The effect of moisture contents of material and their temperatures are of great importance in heat and mass transfer during microwave treatment and affecting penetration depth into the food 
material and determines the success of heating process. Milk, tomato and strawberries juices were tested.

\section{Dielectric capacitance construction:}

The dielectric capacitance, as shown in Fig.(1) consists of two electrodes of $4 \mathrm{~mm}^{2}$ surface area and $2 \mathrm{~mm}^{2}$ distant apart. Material temperature was controlled by using air ventilated oven. For measuring the dielectric constant samples are positioned between the two electrodes and the change of the capacity of the material due to its moisture content and temperature was measured.

1, 2 To the capacitance meter

3, 10 Perforated shelves

4,9 Wood panels for preventing direct

convection.

8 Tested sample position.

7 Plastic frame controlling

distance between the two cupper

electrodes.

6,11 Two copper electrodes .

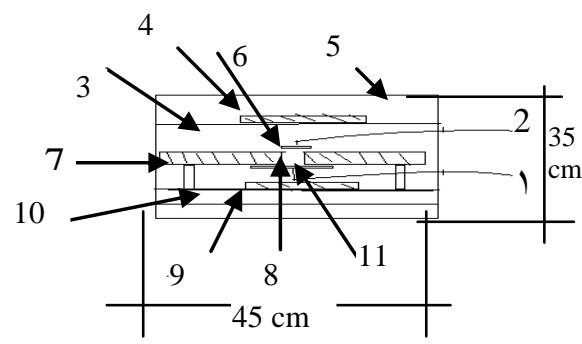

5 controlled temperature enclosur

Fig(1): Experimental setup of the dielectric capacitance.

\section{Measuring instrumentations:}

1-Thermocouples :Temperatures were measured using type-K thermocouples. The output device includes a large 4-digits temperature reading display and electronic circuitry, the specifications of thermocouples are U.S.A manufactured, model 8528-40, full accuracy $18-28^{\circ} \mathrm{C}$ and useful range $4-45^{\circ} \mathrm{C}$

2- Electrical oven, used for controlling temperature $250 \mathrm{oC}, 230 \mathrm{~V}$ AC 50/60 Hz 1200 W Model no. 990462, made in Germany.

3- Mulyimeter: used for measuring capacitance made in Tywan DC $9 \mathrm{~V}$ serial no. 80301370.

4- Conductivity meter: For measuring electrical conductivity in microSiemens/cm , measuring range 0-1999, made in Germany, model no. 2C 10-001.

5- Refractometer, 0-32\%, ATA90N1 Brix, hand refractometer, mad in Japan. 


\section{METHODS}

Three different temperatures and six different moisture contents for milk, tomato and strawberries juices were tested.

\section{Material permittivity $\varepsilon$ :}

The permittivity of tested samples was measured according to Thraja (1993) as follows:

$$
\varepsilon=\mathbf{C} \mathbf{d} / \mathbf{A}
$$

Where:

$\mathrm{C}:$ is the capacitance of the food material in farad,

$\mathrm{d}:$ is the distance between the two electrodes of the capacitance m;

A : is the surface area of the electrode $\mathrm{m}^{2}$.

\section{Relative permittivity $\varepsilon^{\prime}$ :}

The dielectric constant or relative permittivity of the food material can be determined according to Thraja (1993) as follows:

$$
\varepsilon^{\prime}=\varepsilon / 8.85 \times 10^{-12}
$$

\section{Dielectric loss factor $\varepsilon^{\prime \prime}$ :}

The dielectric loss factor can be determined according to the ASAE (1994) as follows:

$$
\varepsilon^{\prime \prime}=\sigma /\left(55.36(2450)\left(10^{-12}\right)\right)
$$

Where :

$\sigma:$ is the electrical conductivity of the food material which can be measured by the conductivity meter in $\mu$ semins $/ \mathrm{cm}$.

\section{Loss Tangent tan $\delta$ :}

The loss tangent can be calculated as follows:

$$
\tan \delta=\varepsilon^{\prime \prime} / \varepsilon^{\prime}
$$

\section{Penetration depth of microwave radiations into material $\lambda_{d}$ :}

Penetration depth of microwave radiations into material can be detrmined according to Lain et al. (1997) as follows:

$$
\lambda_{d}=\lambda_{0} / 2 \pi\left\{2 /\left[\varepsilon^{\prime}\left(1+(\tan \delta)^{2}\right)^{1 / 2}+1\right]\right\}^{1 / 2}
$$

Where: 
$\lambda_{\mathrm{d}}$ : is the penetration depth of the material in $\mathrm{cm}$;

$\lambda_{\mathrm{o}}$ : is the wave length in free space which is $12.24 \mathrm{~cm}$ at $2450 \mathrm{MHz}$.

\section{RESULTS AND DISCUSSIONS}

Figs.(1) and (A-!) show the loss factor of milk, tomato and strawberries juices as affected by their moisture contents and temperatures. It is clear that as the moisture content of the food material and its temperature increase, the loss factor increases and determines the dissipation of the microwave energy out of the material or into the material. The best fit equations were of the form :

$$
\left.\varepsilon^{\prime \prime}=A e_{d b}^{B(M C}\right)
$$

Where $\mathrm{MC}_{\mathrm{db}}$ is the moisture content dry basis $\mathrm{A}$ and $\mathrm{B}$ are constants and their coefficients of determination are depicted in Table (1). Figs.(2) and (A-2) show that the loss tangent ( $\tan \delta$ ) decreased with increasing the moisture content indicating the energy lost or dissipated by the material and satisfied a power form as follows:

$$
\tan \delta=\mathbf{A}\left(\mathbf{M C}_{\mathbf{d b}}\right)^{\mathbf{B}}
$$

Where $\mathrm{MC}_{\mathrm{db}} \%$ is the moisture content dry basis, $\mathrm{A}$ and $\mathrm{B}$ are constants and their coefficients of determination are depicted in Table (2). Figs.(3) and (A-3) show that the dielectric constant $\varepsilon^{\prime}$ as affected by moisture content and temperature of the material follows the same trend as dielectric loss factor, $\mathrm{A}$ and $\mathrm{B}$ are constants and their coefficients of determinations are depicted also in Table (1). Table (3) shows the average and standard deviation values of loss factor $\varepsilon$ ", loss tangent Tan $\delta$, dielectric constant $\varepsilon^{\prime}$ and penetration depth $\lambda_{\mathrm{d}}$ in $\mathrm{cm}$ at $2450 \mathrm{MHz}$ for an average material temperature of $35{ }^{\circ} \mathrm{C}$ as affected by moisture content dry basis.

\section{SUMMARY AND CONCLUSION}

The main objective of the present work is to study the effect of milk and tomato , strawberries juices temperatures and moisture contents ,dry basis, on dielectric constant, loss tangent, loss factor and penetration depth at $2450 \mathrm{MHz}$ that affect heat and mass transfer applications by microwave. From the present study we can conclude that: 


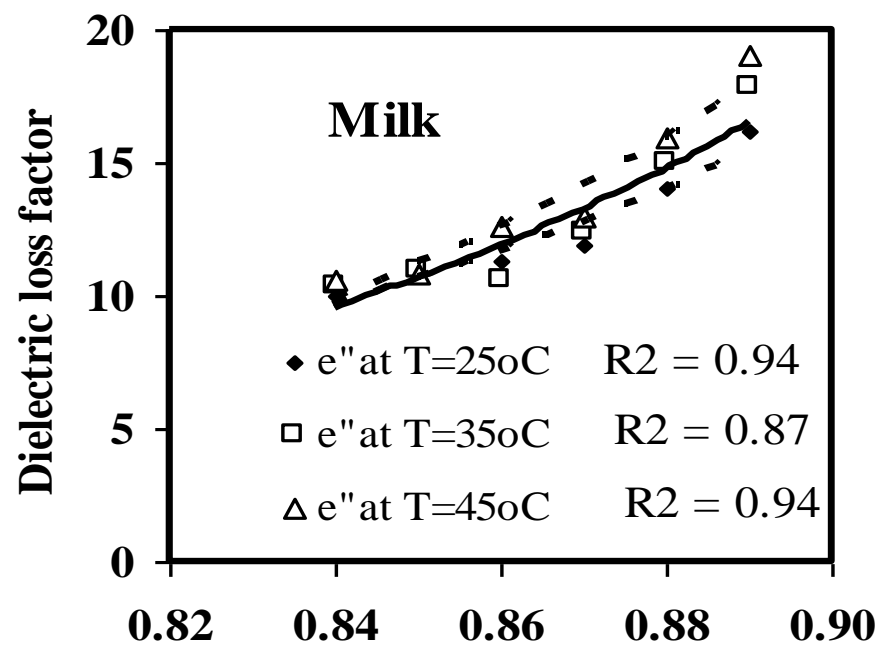

$\mathrm{MC}_{\mathrm{db}} \%$

Fig.(1): Loss factor(dimensionless)of milk as affected by moisture content, dry basis, and its temperature.

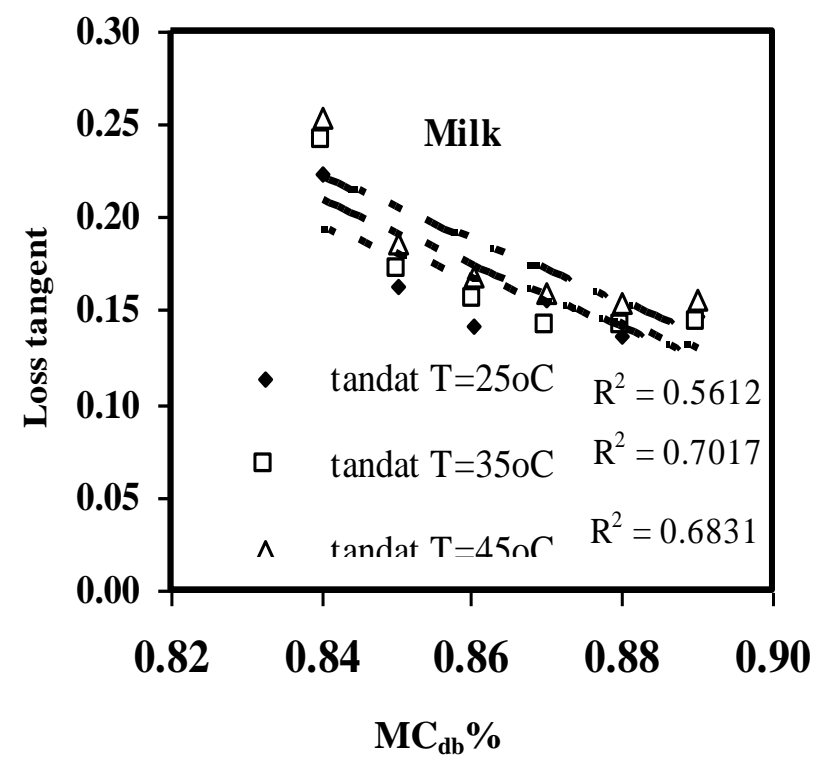

Fig.(2): Loss tangent of milk as affected by their moisture content dry basis and its temperature. 


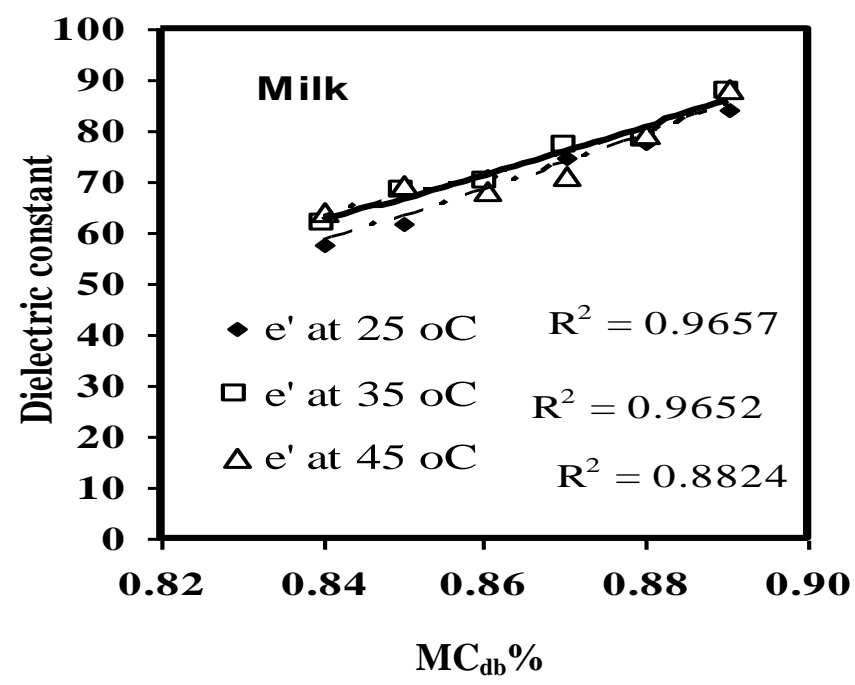

Fig.(3): Dielectric constant of milk as affected by their moisture content, dry basis, and its temperature.

Table(1) Regression coefficients and coefficients of determination (power form equations) of loss factor $\varepsilon^{\prime \prime}$ and dielectric constant $\varepsilon^{\prime}$ (dimensionless) for liquid food material at 25,35 and $45^{\circ} \mathrm{C}$.

\begin{tabular}{|l|c|c|c|c|c|c|c|c|c|c|}
\hline \multicolumn{2}{|l|}{ Temperature } & \multicolumn{3}{|c|}{$25^{\circ} \mathrm{C}$} & \multicolumn{3}{c|}{$35^{\circ} \mathrm{C}$} & \multicolumn{3}{c|}{$45^{\circ} \mathrm{C}$} \\
\hline material & Item & $\mathrm{A}$ & $\mathrm{B}$ & $\mathrm{R}^{2}$ & $\mathrm{~A}$ & $\mathrm{~B}$ & $\mathrm{R}^{2}$ & $\mathrm{~A}$ & $\mathrm{~B}$ & $\mathrm{R}^{2}$ \\
\hline \multirow{3}{*}{ Milk } & $\boldsymbol{\varepsilon}^{\prime \prime}$ & $\mathbf{0 . 0 0 4 2}$ & $\mathbf{0 . 2 2 5 3}$ & $\mathbf{0 . 9 4}$ & $\mathbf{0 . 0 0 1}$ & $\mathbf{1 0 . 8 8}$ & $\mathbf{0 . 8 7}$ & $\mathbf{0 . 0 0 0 5}$ & $\mathbf{1 1 . 7 7}$ & $\mathbf{0 . 9 3}$ \\
\cline { 2 - 12 } & $\boldsymbol{\varepsilon}^{\prime *}$ & 528.1 & -386 & 0.97 & 474.5 & -337 & 0.96 & 436.4 & -304 & 0.88 \\
\hline \multirow{3}{*}{ Tomato } & $\boldsymbol{\varepsilon}^{\prime \prime}$ & $\mathbf{1 9 . 7 3}$ & $\mathbf{0 . 5 8 3}$ & $\mathbf{0 . 8 7}$ & $\mathbf{2 1 . 0 5 4}$ & $\mathbf{0 . 5 5 3}$ & $\mathbf{0 . 8 8}$ & $\mathbf{2 1 . 4 3}$ & $\mathbf{0 . 5 8 5}$ & $\mathbf{0 . 9 2}$ \\
\cline { 2 - 11 } & $\boldsymbol{\varepsilon}^{\prime}$ & $\mathbf{4 7 . 8 7}$ & $\mathbf{0 . 6 0 2}$ & $\mathbf{0 . 9 0 0}$ & $\mathbf{5 0 . 9 5}$ & $\mathbf{0 . 5 7}$ & $\mathbf{0 . 9 1}$ & $\mathbf{5 5 . 3 5}$ & $\mathbf{0 . 4 8 6}$ & $\mathbf{0 . 8 8}$ \\
\hline \multirow{3}{*}{ Strawberries } & $\boldsymbol{\varepsilon}^{\prime \prime}$ & $\mathbf{9 . 7 5}$ & $\mathbf{1 . 0 2}$ & $\mathbf{0 . 9 0}$ & $\mathbf{1 0 . 5 6}$ & $\mathbf{0 . 9 6}$ & $\mathbf{0 . 9 4}$ & $\mathbf{1 1 . 8}$ & $\mathbf{0 . 8 9}$ & $\mathbf{0 . 9 7}$ \\
\cline { 2 - 11 } & $\boldsymbol{\varepsilon}^{\prime}$ & $\mathbf{8 5 . 8 5}$ & $\mathbf{0 . 5 0 0}$ & $\mathbf{0 . 8 3}$ & $\mathbf{6 1 . 2 8}$ & $\mathbf{0 . 5 1 4}$ & $\mathbf{0 . 8 8}$ & $\mathbf{0 . 6 2}$ & $\mathbf{0 . 5 6}$ & $\mathbf{0 . 9 4}$ \\
\hline
\end{tabular}

* Best fit form is linear, A represents the slope.

Table(2) Regression coefficients and coefficients of determination ( power form equations) of loss tangent $\operatorname{Tan} \delta$ for liquid food material at 25,35 and $45^{\circ} \mathrm{C}$.

\begin{tabular}{|c|c|c|c|c|c|c|c|c|c|c|}
\hline \multicolumn{2}{|c|}{ Temperature } & \multicolumn{3}{|c|}{$25^{\circ} \mathrm{C}$} & \multicolumn{3}{c|}{$35^{\circ} \mathrm{C}$} & \multicolumn{3}{c|}{$45^{\circ} \mathrm{C}$} \\
\hline material & Item & $\mathrm{A}$ & $\mathrm{B}$ & $\mathrm{R}^{2}$ & $\mathrm{~A}$ & $\mathrm{~B}$ & $\mathrm{R}^{2}$ & $\mathrm{~A}$ & $\mathrm{~B}$ & $\mathrm{R}^{2}$ \\
\hline Milk & Tan $\delta$ & -0.06 & -1.51 & 0.77 & -0.67 & -1.65 & 0.78 & -0.65 & -1.74 & 0.75 \\
\hline Tomato & Tan $\delta$ & 0.17 & -0.12 & 0.99 & 0.179 & -0.12 & 0.99 & 0.195 & -0.12 & 0.98 \\
\hline Strawberries & Tan $\delta$ & 0.06 & -0.09 & 0.94 & 0.08 & -0.09 & 0.97 & 0.09 & -0.09 & 0.98 \\
\hline
\end{tabular}


Table(3) Average and standard deviation values of loss factor $\varepsilon^{\prime \prime}$, loss tangent Tan $\delta$, dielectric constant $\varepsilon^{\prime}$ and penetration depth $\lambda_{\mathrm{d}}$ in $\mathrm{cm}$ at $2450 \mathrm{MHz}$ for an average material temperature of $35{ }^{\circ} \mathrm{C}$ as affected by moisture content dry basis.

\begin{tabular}{|c|c|c|c|c|c|c|c|c|c|}
\hline & $\begin{array}{c}\mathbf{M C}_{\mathrm{db}} \\
\%\end{array}$ & \multicolumn{4}{|c|}{ Average } & \multicolumn{4}{|c|}{ Standard deviation } \\
\hline \multicolumn{2}{|c|}{ Material } & $\varepsilon^{\prime \prime}$ & $\operatorname{Tan} \delta$ & $\varepsilon^{\prime}$ & $\lambda_{\mathrm{d}}$ & $\varepsilon^{\prime \prime}$ & $\begin{array}{l}\text { Tan } \\
\delta\end{array}$ & $\varepsilon^{\prime}$ & $\lambda_{\mathrm{d}}$ \\
\hline \multirow{6}{*}{ Milk } & 0.89 & 17.7 & 0.13 & 86.8 & 0.28 & 1.405 & 0.012 & 2.164 & 0.123 \\
\hline & 0.88 & 14.9 & 0.14 & 78.4 & 0.29 & 0.950 & 0.010 & 0.684 & 0.125 \\
\hline & 0.87 & 12.4 & 0.16 & 74.2 & 0.31 & 0.524 & 0.008 & 2.84 & 0.127 \\
\hline & 0.86 & 11.5 & 0.18 & 70.0 & 0.314 & 1.055 & 0.014 & 1.423 & 0.128 \\
\hline & 0.85 & 10.8 & 0.20 & 66.6 & 0.325 & 0.062 & 0.018 & 3.97 & 0.147 \\
\hline & 0.84 & 10.3 & 0.23 & 61.2 & $\mathbf{0 . 3 3 8}$ & 0.276 & 0.015 & 3.47 & 0.152 \\
\hline \multirow{6}{*}{ Tomato } & 0.92 & 36.1 & 0.20 & 86.8 & 0.417 & 1.418 & 0.015 & 2.56 & 0.007 \\
\hline & 0.76 & 33.6 & 0.22 & 81.3 & 0.43 & 0.979 & 0.018 & 1.488 & 0.005 \\
\hline & 0.58 & 26.8 & 0.23 & 69.3 & 0.466 & 2.03 & 0.009 & 3.055 & 0.011 \\
\hline & 0.41 & 25.1 & 0.27 & 58.2 & 0.507 & 1.952 & 0.009 & 3.503 & 0.016 \\
\hline & 0.22 & 23.3 & 0.35 & 58.3 & 0.501 & 1.06 & 0.012 & 3.308 & 0.015 \\
\hline & 0.1 & 23.3 & 0.47 & 57.5 & 0.494 & 1.12 & 0.015 & 4.050 & 0.019 \\
\hline \multirow{6}{*}{ Strawberries } & 0.93 & 26.2 & 0.09 & 104.1 & 0.507 & 1.029 & 0.009 & 4.007 & 0.208 \\
\hline & 0.78 & 23.6 & 0.11 & 92.6 & 0.54 & 0.88 & 0.011 & 5.901 & 0.219 \\
\hline & 0.59 & 18.2 & 0.12 & 76.8 & 0.591 & 1.353 & 0.017 & 3.412 & 0.241 \\
\hline & 0.43 & 15.0 & 0.13 & 72.13 & 0.61 & 1.05 & 0.018 & 4.007 & 0.248 \\
\hline & 0.23 & 13.0 & 0.21 & 68.0 & 0.625 & 1.026 & 0.019 & 4.00 & 0.254 \\
\hline & 0.21 & 12.8 & 0.28 & 69.0 & 0.608 & 1.265 & 0.006 & 1.029 & 0.251 \\
\hline
\end{tabular}

1- The loss factor increases as the moisture content of the food material and its temperature increases, and determines the dissipation of the microwave energy out of the material or into the material. The best fit equations were of the form :

$$
\varepsilon^{\prime \prime}=\mathrm{A} \mathrm{e}_{\mathrm{db}}^{\mathrm{B}\left(\mathrm{MC}_{\mathrm{b}}\right),}
$$

where $\mathrm{MC}_{\mathrm{db}}$ is the moisture content dry basis ,A and B are constants with coefficients of determination ranging between 0.88-0.97. 
2- Loss tangent $(\tan \delta)$ decreased with increasing the moisture content indicating the energy lost or dissipated by the material and satisfied a power form as follows:

$$
\tan \delta=A\left(M_{d b}\right)^{B}
$$

Where $\mathrm{MC}_{\mathrm{db}}$ is the moisture content dry basis , $\mathrm{A}$ and $\mathrm{B}$ are constants with coefficients of determinationranging between 0.94-0.99 .

3- Dielectric constant $\varepsilon^{\prime}$ follows the same trend as dielectric loss factor.

4- This study helps as a data base for microwave heat and mass transfer applications and for calculating penetration depth.

\section{RFERENCES}

Abd El Hameid, El-S.Abd El-H.2001.Mechanization of scalded milk cream process. PhD. Th. of Ag.Eng. Fuc. of Agr. Al-Azhar Univ.

ASAE.1994.Standared, Engineering practice data.ISBNo-929355-50. Lib. of Congress. By Am. Soci. of Ag. Eng:459-466.

Karamas.E.1980 Techniques for measurement of moisture content of foods. Food Tec. April: 52-59.

Lain,G., Harris.C.S,Evens,R. and Waboys,M.1997.Coupled Heat and moisture transfer during vacuum drying. J. Microwave power electromagnetic Energy. 32:34-44. (C.f. Mujamdar, 2001).

Mujamdar,A.S. 2000. Drying technology in agriculture and food science Pub., Inc. Enfield, New Hampshire 03784 U.S.A Ch. 10:253-286.

Mulin,J1995. New method of food preservstion(microwave processing). Blackie Acad.\& prof., N. Y.: (C.f. AbdEl Hamid 2000).

Theraja,B.L.1993. A text book electrical technology. Pub. div. of Nirja Constr. \& Dev. Co.(p) LTD RAM NAGAR,New Delhi-100055:118160.

Toledo,R.T.1991.Fudamentals of food process engineering. An AVI book Pub. By Van Nostrand Reinhold.N.Y.10003.ISBN. o-442-239886:133-136. 


\section{$\underline{\text { APPENDIX }}$}
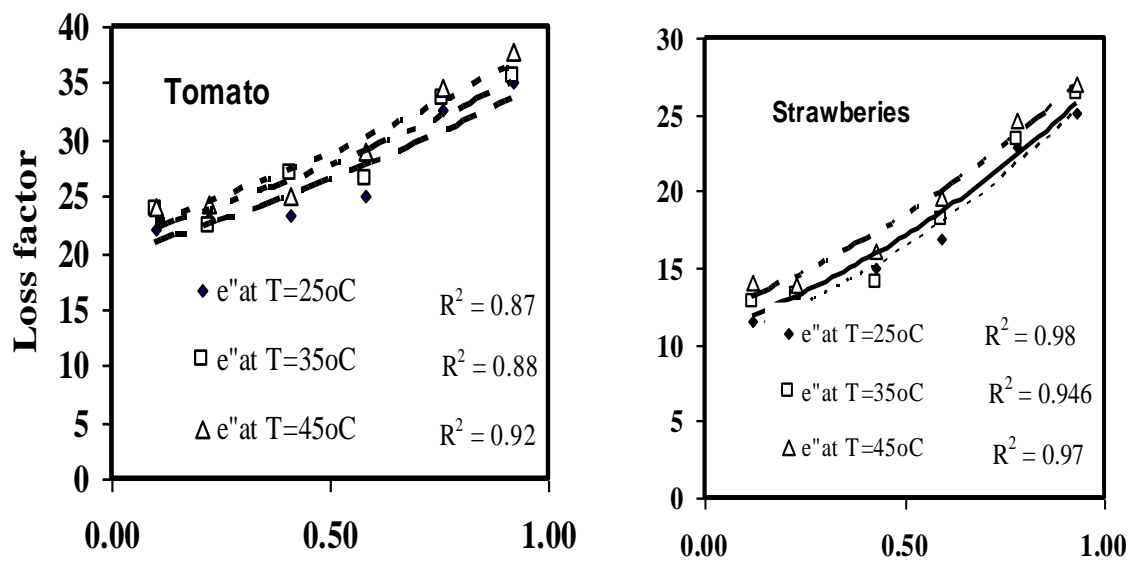

$\mathrm{MC}_{\mathrm{db}} \%$

Fig.(1-A) Loss factor(dimensionless)of Tomato and strawberries as affected by moisture content, dry basis, and its temperature.
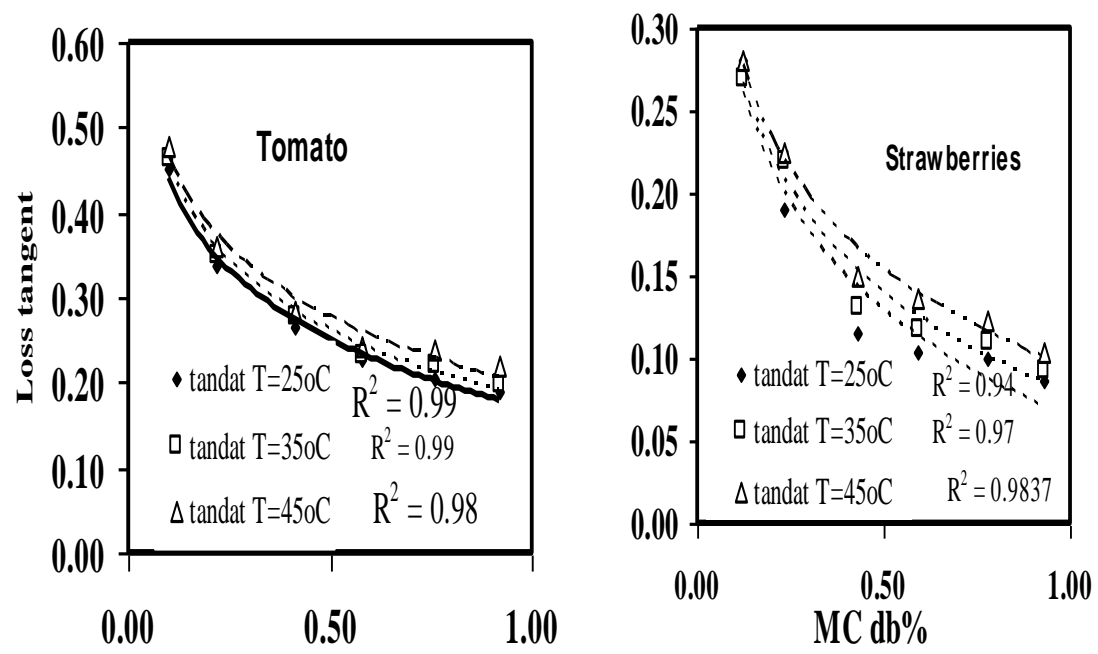

$\mathrm{MC}_{\mathrm{db}} \%$

Fig.(2-A) Loss tangent(dimensionless)of Tomato and strawberries as affected by moisture content, dry basis, and its temperature. 


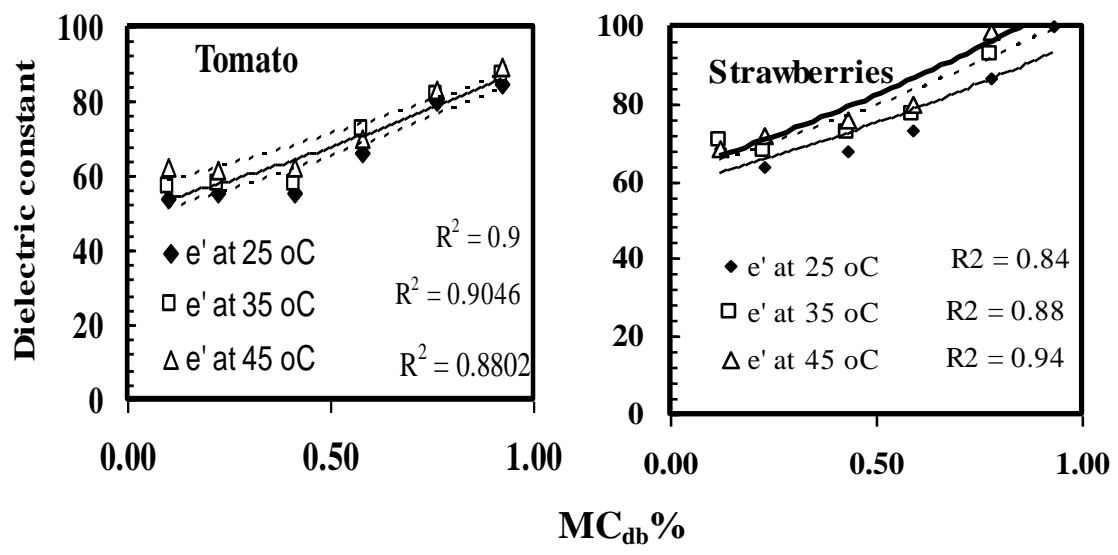

Fig.(3-A) Loss tangent(dimensionless)of Tomato and strawberries as affected by moisture content, dry basis, and its temperature.

خواص العزل لبعض مواد الغذاء السائلة ومدى العزئئر ها بالمحتوى الرطوبى ودرجة

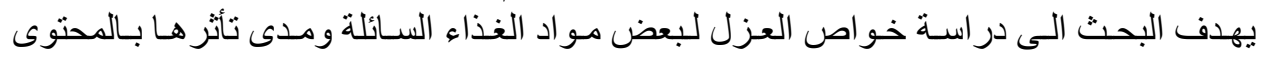

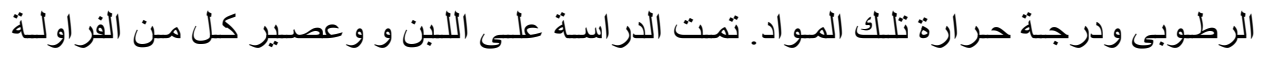

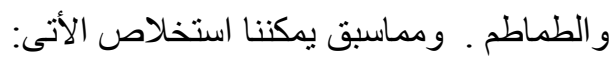

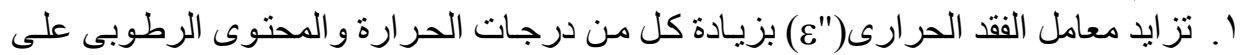
اساس جاف $\varepsilon^{\prime \prime}=A e^{B(M C)}$

حيث (A) و (B) ثوابت تختلف باختلاف المادة .

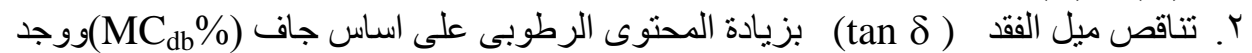

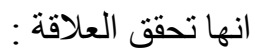

$$
\tan \delta=\mathbf{A}\left(\mathbf{M C}_{\mathrm{db}}\right)^{\mathbf{B}}
$$

و خاصية معامل الفقد نفس

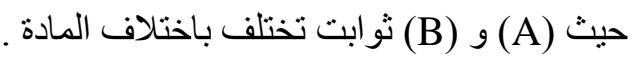

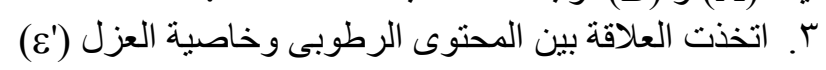

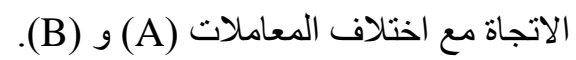

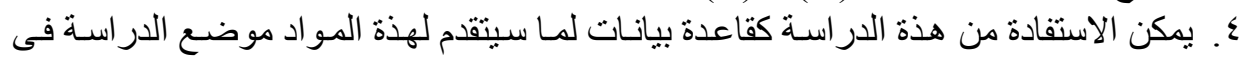
تطبيقات انتقال المادة و الحر ارة باستخدام الميكرويف.

*أستاذ مساعد الهندسة الزراعية ـ كلية الزر اعة بالقاهرة - جامعة الأزهر. 